Revista de la red interuniversitaria de estudios sobre las literaturas rioplatenses contemporáneas en Francia

9| 2013

Homenaje a Ana María Barrenechea

\title{
Los poderes de la fantasía
}

\author{
Marcos Seifert
}

\section{OpenEdition}

Journals

Edición electrónica

URL: http://journals.openedition.org/lirico/1214

DOI: 10.4000/lirico.1214

ISSN: 2262-8339

Editor

Réseau interuniversitaire d'étude des littératures contemporaines du Río de la Plata

\section{Referencia electrónica}

Marcos Seifert, «Los poderes de la fantasía », Cuadernos LIRICO [En línea], 9 | 2013, Publicado el 01

septiembre 2013, consultado el 22 septiembre 2020. URL : http://journals.openedition.org/lirico/1214 ; DOI : https://doi.org/10.4000/lirico.1214

Este documento fue generado automáticamente el 22 septiembre 2020

\section{(c) (i) (9)}

Cuadernos LIRICO está distribuido bajo una Licencia Creative Commons Atribución-NoComercialSinDerivar 4.0 Internacional. 


\title{
Los poderes de la fantasía
}

\author{
Marcos Seifert
}

\section{REFERENCIA}

Gasparini, Sandra, Espectros de la ciencia. Fantasías científicas de la Argentina del siglo XIX, Buenos Aires, Santiago Arcos Editor, 2012, 335 p. 
1 Estudiar un género literario - la fantasía científica- en relación con los avatares de la institucionalización de la ciencia y con los procesos de modernización en la Argentina permite a Sandra Gasparini una redefinición del corpus canónico de la literatura argentina del siglo XIX. Gasparini rescata y recoloca, en una red intertextual de visibilidad y relevancia, una serie de textos postergados por no pertenecer al grupo de obras recurrentes en las antologías o por no ser del gusto de una crítica que suele preferir la literatura fantástica o de ciencia ficción. Esta textualidad heterogénea, que como señala la autora se sitúa en el borde de los géneros y los saberes y es el lugar de su intersección, queda fuera de una tendencia a concentrar el análisis literario

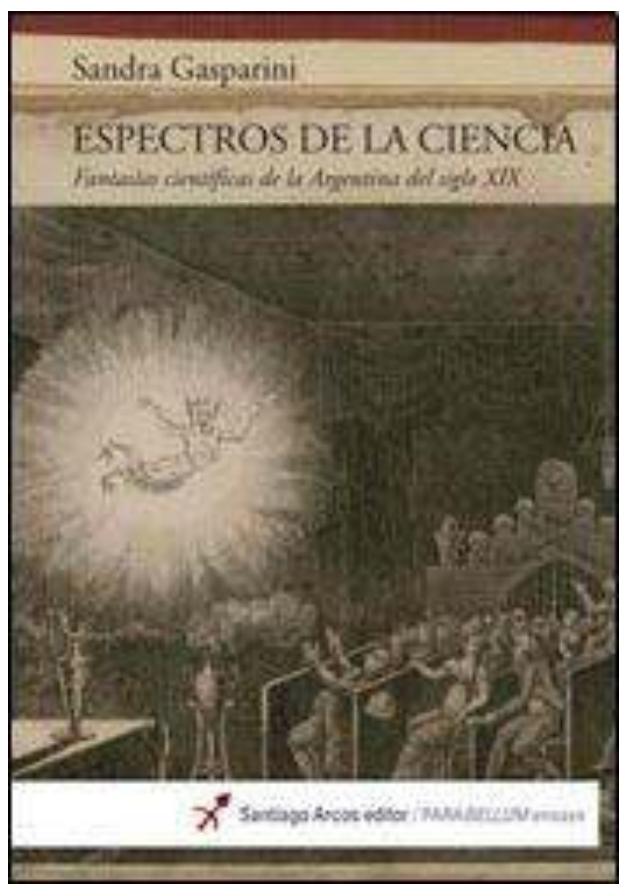
en una lista de libros representativos, autorizados y reconocidos. Consciente de esta intervención sobre la cuestión canónica, Gasparini esquiva con inteligencia la noción de precursor, que implicaría colocar el abordaje crítico en el lugar del descubrimiento de aquellos que incurrieron en estrategias y temáticas luego perfeccionadas por autores del canon. Gasparini amplía los límites del corpus jerárquico según la convicción de Harold Bloom de que "toda poderosa originalidad literaria se convierte en canónica"1.

2 El trabajo de la autora, al dar cuenta de la especificidad de la fantasía científica argentina y abordar con minuciosidad su momento de emergencia, no sólo recupera textos soslayados, sino que también reflota redes de reescritura inadvertidas y desempolva polémicas relegadas. Espectros de la ciencia pretende y logra persuadir acerca de la relevancia de la fantasía científica hacia finales del siglo XIX. A pesar de que Gasparini se extiende también en la relación estrecha de los textos con la prensa periódica, las políticas científicas y los nuevos modos de sociabilidad, el centro de su análisis es siempre el texto literario, cuya comprensión es enriquecida por el preciso desarrollo de las condiciones de producción y los debates científicos del período. En este sentido, la argumentación toma en cuenta la potencialidad literaria de transformación de los repertorios y las querellas científicas, a la vez que señala el lugar de divulgación de ideas que las ficciones asumen deliberadamente. Cuando Gasparini trabaja la elección del subtítulo de "fantasía científica" por parte de Eduardo Holmberg para su texto Dos partidos en lucha, advierte el uso estratégico que hace el escritor naturalista de tal designación. Con esa nominación, señala la autora, Holmberg inaugura "[...] un proyecto estético que considera a la literatura como lugar apropiado desde el cual alentar una polémica sobre políticas de la ciencia y de la educación (104)”.

Los textos no dejan de aprovechar su condición estética para trabajar en los límites del discurso científico a partir de géneros como el ensueño, "que propuso una zona de contacto entre el razonamiento deductivo y la creación poética" (135), o incorporar hipótesis descartadas o consideradas erróneas por el ámbito académico. Gasparini 
expone cómo los autores de las fantasías científicas retoman y se apropian de diversos recursos narrativos mediante los cuales incorporan o discuten el saber académico desde cierta distancia o desde un ángulo deformante. Espectros de la ciencia aborda los textos del período en tanto experimentos sobre experimentos, laboratorios de formas que permiten pensar, además, la consolidación de la esfera literaria.

Para calibrar el alcance de esta experimentación, el trabajo de Gasparini aborda también planteos teóricos que permiten reflexionar sobre el problema del verosímil en la ficción científica. A diferencia de la poética de la narración fantástica que exhibe un desequilibrio entre verosimilitud e invención, las ficciones científicas nos presentan un verosímil enrarecido que, si bien se ajusta al referente histórico, "usa dispositivos que fuerzan lo admisible en los sucesos de la narración" (19). De esta manera, Gasparini adopta una perspectiva que tiene en cuenta la intervención que realizan las ficciones en los modos de percepción de la realidad de los lectores. Si, como señala Marc Angenot, las narraciones literarias son responsables del "simulacro de una gnoseología del sentido común" y de la producción de "lo típico y lo verosímil" que ofrecen al lector una manera de conocer el mundo, ${ }^{2}$ en el caso de las ficciones científicas la verosimilitud construida -señala Gasparini- entra en colisión con la versión de la realidad legitimada por el discurso de la academia científica.

5 Mientras que el modelo de las comunicaciones científicas responde a un circuito cerrado y homogéneo entre pares, la ficción científica, tal como la entendió Holmberg, se presentaría como un aparato de divulgación para que los saberes y debates rompan el cerco del ámbito académico y adquieran mayor resonancia desde un feedback constante con las publicaciones periódicas de la época. El trabajo de la ficción también se apoya en la ficcionalización de la relación compleja que establecen los jóvenes ayudantes de científicos con los ancianos "doctores" representantes del antiguo orden. Los sujetos históricos devienen sujetos ficcionales que plantean la discusión acerca de quiénes deben ser las figuras legítimas para llevar adelante el proceso de modernización científica en el país.

6 En lugar de esquemas simplificadores de herencias e influencias directas, se propone un sistema de reescrituras de aspectos genéricos, matrices temáticas y recursos narrativos que no recae en la dicotomía de una periferia dependiente de un centro. Géneros como las novelas de anticipación y las utopías siderales constituyeron modelos a partir de los cuales la ficción científica argentina se apropia y procede a recombinar elementos que posibilitan narrar los debates y preocupaciones locales inherentes al proceso de institucionalización de la ciencia. La autora entiende que, para describir el momento de emergencia de un género como la fantasía científica, la complejidad debe hallarse en las interrelaciones dinámicas entre tradiciones, instituciones y textos. Por eso mismo, también, atiende al carácter residual de los repertorios temáticos y retóricos en los términos de Raymond Williams : lo residual como aquello que ha sido formado en el pasado, pero todavía participa en el proceso cultural ${ }^{3}$. De esta manera, Gasparini echa luz sobre el laberinto de préstamos y apropiaciones genéricas a la vez que identifica el entramado de discursos sociales, políticos y científicos que se tironean y se solapan en cada narración. Si la fantasía científica se pregunta qué hacer con los saberes y cuestiona sus alcances y características, el trabajo crítico de Gasparini se interroga sobre cómo operan con ellos concretamente tales narraciones, y al mismo tiempo revela el zurcido de discursos sociales y la connivencia de saberes integrados en textos cuyo denominador común es la interpelación al lector. Espectros de la ciencia destaca con 
vehemencia la potencia ilocutiva de las narraciones. Su performatividad no es la ya abordada de las obras fundantes del siglo XIX, que desarrollan un proyecto de nación y establecen las bases del Estado liberal, sino que se trata de una praxis literaria de intervención tanto en los debates sobre políticas científicas y educativas, como de cuestionamiento de la idea de progreso indefinido que atraviesa los discursos de la época.

7 El análisis del corpus recala, en primer lugar, en algunos cuentos de J. M. Gorriti que se encuentran atravesados por elementos de la estética gótica y romántica. En ellos se destaca el diálogo entre los saberes científicos y las prácticas populares que luego marcará fuertemente a las ficciones científicas de las décadas del 70 y 80 . El relato del Cabo Gómez escrito por Lucio Mansilla en su célebre Una excursión a los indios ranqueles de 1870, junto a algunas de sus causeries, ponen en escena, también, saberes emergentes de la época, como el magnetismo y los fenómenos psíquicos que, años después, se vuelven relevantes para el género. El lugar central del corpus lo ocupa Eduardo Holmberg, intelectual, naturalista, médico y entomólogo, cuyos textos no sólo dramatizan las disputas científicas, sino que tienen como eje la representación de los avatares de la institucionalización de la ciencia en Argentina. El género literario que funda Holmberg, además de incorporar las teorías científicas en la ficción, aprovecha la autonomía de la esfera literaria respecto al rigor de la metodología de las ciencias para polemizar con la academia y cuestionar los alcances del saber científico. También se incluyen en el libro relatos que, a diferencia de los textos de Holmberg, no tienen un autor "científico". Algunas producciones narrativas de Carlos Olivera, Carlos Monsalve y Luis V. Varela reformulan interrogantes de la fantasía científica (el lugar de la ciencia en relación con el Estado, los límites entre la razón y la locura) y exhiben su estrecho vínculo con la prensa, rasgo constitutivo del género. Gasparini destaca las inflexiones e intereses particulares que emergen en cada caso. Si en El doctor Whüntz de Varela a la narración de los debates científicos se le suma el saber de la jurisprudencia, en "Fantasía nocturna" de García Mérou adquiere centralidad la figura del médico higienista. Para analizar estos textos de la década del 80 y principios del 90, Gasparini recurre a las narraciones de Holmberg en tanto configuradoras de una matriz narrativa que será apropiada o reformulada por relatos posteriores. De esta manera, el análisis de la utopía de Achilles Sioen y la distopía de Eduardo Ezcurra permite a la autora considerar la reescritura de tópicos y repertorios establecidos por Viaje maravilloso del señor Nic-Nac al planeta Marte de Holmberg (1875) en otras condiciones históricas de producción. Finalmente, Gasparini incorpora las lecturas de algunas reseñas de la época para perfilar "un mapa de recepción del género" (277). La decisión de repasar las reseñas contemporáneas a la publicación de algunos textos es coherente con la voluntad de reconstruir las redes interdiscursivas e intertextuales que permitan visibilizar un género soslayado por la historia literaria.

8 Por último, cabe destacar la distancia entre este libro y cierta crítica literaria académica que no escatima esfuerzos para ocultar sus pasiones y sus "afinidades electivas". Muy por el contrario, la labor crítica de Sandra Gasparini en Espectros de la ciencia no puede escindirse de su pasión por la ficción científica argentina del siglo XIX. 


\section{NOTAS}

1. H. Bloom, El canon occidental, Barcelona, Anagrama, 2005, p. 35.

2. M. Angenot, Interdiscursividades. De hegemonías y disidencias, Córdoba, Editorial Universidad Nacional de Córdoba, 1998, p. 79.

3. R. Williams, Marxismo y literatura, Barcelona, Península, 1997, p. 144

\section{AUTORES}

\section{MARCOS SEIFERT}

Universidad de Buenos Aires- CONICET 